\title{
A novel kartogenin-platelet-rich plasma gel enhances chondrogenesis of bone marrow mesenchymal stem cells in vitro and promotes wounded meniscus healing in vivo
}

\author{
Feng Liu', Hongyao Xu' ${ }^{2}$ and He Huang ${ }^{2,3^{*}}$ (1)
}

\begin{abstract}
Background: The meniscus tear is one of the most common knee injuries particularly seen in athletes and aging populations. Subchondral bone sclerosis, irreparable joint damage, and the early onset of osteoarthritis make the injured meniscus heal difficultly.
\end{abstract}

Methods: The study was performed by in vitro and in vivo experiments. The in vitro experiments were carried out using the bone marrow stem cells (BMSCs) isolated from the rabbits, and the stemness of the BMSCs was tested by immunostaining. The BMSCs positively expressed stem cell markers were cultured with various concentrations of kartogenin (KGN) for 2 weeks. The chondrogenesis of BMSCs induced by KGN was examined by histochemical staining and quantitative RT-PCR. The in vivo experiments were completed by a rabbit model. Three holes were created in each meniscus by a biopsy punch. The rabbits were treated with four different conditions in each group. Group 1 was treated with $20 \mu \mathrm{l}$ of saline (saline); group 2 was treated with $5 \mu \mathrm{l}$ of $100 \mu \mathrm{M} \mathrm{KGN}$ and $15 \mu \mathrm{l}$ saline (KGN); group 3 was treated with $5 \mu \mathrm{l}$ of $100 \mu \mathrm{M} \mathrm{KGN}, 5 \mu \mathrm{l}$ of 10,000 $\mathrm{U} / \mathrm{ml}$ thrombin, and $10 \mu \mathrm{l}$ of PRP (KGN+PRP); group 4 was treated with 10,000 BMSCs in $10 \mu \mathrm{l}$ of PRP, $5 \mu \mathrm{l}$ of saline solution, and $5 \mu \mathrm{l}$ of 10,000 $\mathrm{U} / \mathrm{ml}$ thrombin (PRP+BMSC); group 5 was treated with 10,000 BMSCs in $10 \mu \mathrm{l}$ of PRP, $5 \mu \mathrm{l}$ of $100 \mu \mathrm{M} \mathrm{KGN}$, and $5 \mu \mathrm{l}$ of 10,000 $\mathrm{U} / \mathrm{ml}$ thrombin (KGN+PRP+BMSC). The menisci were collected at day 90 post-surgery for gross inspection and histochemical analysis.

Results: The histochemical staining showed that KGN induced chondrogenesis of BMSCs in a concentration-dependent manner. The RT-PCR results indicated that chondrocyte-related genes were also increased in the BMSCs cultured with KGN in a dose-dependent manner. The in vivo results showed that large unhealed wound areas were still found in the wounds treated with saline and KGN groups. The wounds treated with BMSCs-containing PRP gel healed much faster than the wounds treated without BMSCs. Furthermore, the wounds treated with BMSCs-containing KGN-PRP gel have healed completely and formed more cartilage-like tissues than the wounds treated with BMSCs-containing PRP gel.

Conclusions: BMSCs could be differentiated into chondrocytes when they were cultured with KGN-PRP gel in vitro and formed more cartilage-like tissues in the wounded rabbit meniscus when the wounds were treated with BMSCscontaining KGN-PRP gel. The results indicated that the BMSCs-containing KGN-PRP gel is a good substitute for injured meniscus repair and regeneration.

Keywords: Kartogenin, PRP, BMSCs, Chondrogenesis, meniscus injury, Meniscus regeneration

\footnotetext{
* Correspondence: riversh922@hotmail.com

${ }^{2}$ Department of Sports Medicine and Joint Surgery, Nanjing First Hospital,

Nanjing Medical University, 68 Changle Road, Nanjing 210006, Jiangsu, China

${ }^{3}$ China Orthopaedic Regeneration Medicine Group, Zhejiang 310000,

Hangzhou, China

Full list of author information is available at the end of the article
}

(c) The Author(s). 2019 Open Access This article is distributed under the terms of the Creative Commons Attribution 4.0 International License (http://creativecommons.org/licenses/by/4.0/), which permits unrestricted use, distribution, and reproduction in any medium, provided you give appropriate credit to the original author(s) and the source, provide a link to the Creative Commons license, and indicate if changes were made. The Creative Commons Public Domain Dedication waiver (http://creativecommons.org/publicdomain/zero/1.0/) applies to the data made available in this article, unless otherwise stated. 


\section{Background}

Meniscus is a rubbery tissue located between the femoral condyle and tibial plateau of the knee and aids in the force transmission, shock absorption, joint stability, lubrication, and proprioception of the knee joint [1-3]. The meniscus was dissected into inner and outer zones. The structure and composition of the two zones are different. The inner zone of the meniscus is an avascular/aneural region (whitewhite zone) with an articular cartilage-like structure, and the cells produce predominantly type II collagen and proteoglycans. The outer zone of the meniscus is a vascular/ neural region (red-red zone) with a fibrocartilage-like structure and composed of cells with a higher proportion of type I collagen. These two areas are separated by the red-white region, which presents attributes from both redred and white-white regions. The anatomical difference in the vascular supply limits the ability of meniscus to heal. It has been reported that the healing capacity of each area is directly related to blood circulation, leaving the white region susceptible to permanent post-traumatic and degenerative lesions [4].

Meniscus tears are very common injuries which occurred in athletes and aging populations [1]. If the injury happens at white-white zone or red-white zone, the injured meniscus heals poorly due to the lack of blood flow [5]. Currently, the injured menisci are treated surgically by partial or total meniscectomy [4]. Both procedures have shown poor long-term clinical results as evidenced by articular cartilage degeneration, articular surface flattening, subchondral bone sclerosis, irreparable joint damage, and the early onset of osteoarthritis [3]. The studies have found that meniscectomy can cause osteoarthritis [6, 7]. Although new techniques such as meniscal rasping and implantation of the synovial flap for enhancing the injured meniscus healing have been developed, the absence of healing, suboptimal repair outcomes with lengthy repair times were found in the inner avascular zone $[1,8]$. Meniscal allograft transplantation (MAT) is considered a potential solution to restore knee biomechanics, improve clinical outcomes, and, possibly, delay the onset of knee osteoarthritis (OA) and has been widely used in recent years $[9,10]$. However, there are still several controversial issues related to MAT. The chondroprotective effect of MAT is still not completely proven [11]. Furthermore, the failure of transplant is always occurred by immunoreactions, and the risk of disease transmission also limits allograft transplantations [12].

Tissue engineering is a newly emerging biomedical technology and methodology based on a smart and unique combination of cells, growth factors, and scaffolds to assist and accelerate regenerating and repairing of defective and damaged tissues $[13,14]$. The animal experimental results have demonstrated that mesenchymal stem cell (MSC)based tissue engineering technique provides a promising alternative for repairing injured meniscus due to their multi- differentiation potential $[15,16]$. Using a stem cell-based approach to repair the damaged cartilage has shown promising results [17].

Recently, a small heterocyclic compound named kartogenin (KGN) was demonstrated to promote robust chondrocyte differentiation of the MSCs of humans [17], rabbits [18], and rats [19]. We also found that the KGN-treated autologous tendon graft can be used as a meniscal implant for meniscus regeneration [20].

Platelet-rich plasma (PRP) is an autologous plasma fraction containing high concentrations of platelets enriched with various growth factors such as platelet-derived growth factor (PDGF), transforming growth factor (TGF), and vascular endothelial growth factor (VEGF) and known to accelerate healing of tissues [21]. Several clinical studies have demonstrated that PRP injections have improved function and decreased pain to various maladies, including the elbow, wrist shoulder, hip, knee, ankle, plantar fascia, and meniscus [22-26].

There are two key considerations for repairing a damaged meniscus. The first consideration is that the defective area must have enough stem cells, and the second consideration is that the stem cells at the defective area must differentiate into cartilage cells. In order to ensure enough stem cells in the wound area, we injected rabbit BMSCscontaining PRP gel into the defect area. In order to induce the chondrogenic differentiation of these stem cells, we added KGN into the BMSCs-PRP gel to treat the wounded meniscus. Based on the previous studies, we hypothesize that BMSCs can be differentiated into chondrocytes when they are cultured with KGN-containing medium, and enhance meniscal regeneration in vivo when the BMSCs are injected into wounded meniscus with KGN-containing PRP gel together. To test our hypothesis, we isolated BMSCs from rabbit femur bones and determined the effect of KGN-containing PRP gel on the chondrogenic differentiation potential of the BMSCs in vitro, which enhanced the wounded meniscus healing in vivo.

\section{Materials and methods}

Fifteen New Zealand white rabbits (6 months old, female) were used in this study. The experiments were done at Nanjing Medical University (NMU) following the approved protocol by the Institutional Animal Care and Use Committee (IACUC) of NMU.

\section{Isolation of bone marrow-derived stem cells (BMSCs)}

Three rabbits were sedated by intra-muscular injection of ketamine $(10 \mathrm{mg} / \mathrm{kg})$ and xylazine $(3 \mathrm{mg} / \mathrm{kg})$, and then sacrificed with pentobarbital $(120 \mathrm{mg} / \mathrm{kg})$. The BMSCs were isolated from femur bones according to the published protocols [27]. Briefly, a needle (18-gauge) fastened to a syringe containing $0.2 \mathrm{ml}$ of heparin (1000 units $/ \mathrm{ml}$ ) to aspirate 2 $\mathrm{ml}$ of bone marrow followed by washing the aspirates twice 
with phosphate-buffered saline (PBS). The bone marrowPBS solution was centrifuged at $1500 \mathrm{~g}$ for $5 \mathrm{~min}$. After discarding the supernatant, the cells were resuspended in growth medium (20\% fetal bovine serum in DMEM with $1 \%$ of penicillin and streptomycin) and incubated at $37^{\circ} \mathrm{C}$ with $5 \%$ of $\mathrm{CO}_{2}$ and $95 \%$ of air atmosphere.

\section{PRP preparation}

PRP was prepared from autologous blood of the same rabbit based on the previously published protocols [28]. The concentration of the platelet in the PRP was four times higher than that in the whole blood. The blood was collected atraumatically to avoid premature platelet activation by exposure to excessive shear forces.

Briefly, 9 parts of the whole rabbit blood were mixed with 1 part of $3.8 \%$ of sodium citrate (SC); the blood-SC mixture was separated into three layers by a centrifuge at $500 \mathrm{~g}$ for $5 \mathrm{~min}$ (Fig. 1). The top layer was transferred into a new sterile tube and centrifuged at $2000 \mathrm{~g}$ for another $5 \mathrm{~min}$. The supernatant was collected and named as platelet-poor plasma (PPP). The platelet-containing pellet was suspended with appropriate volumes of PPP. The concentration of the platelet in the PRP was measured by automatic hematology analyzer (CELLDYN Emerald, Abbott Laboratories, Chicago, IL, USA) and stored at $4{ }^{\circ} \mathrm{C}$ until further use.

\section{Characterization of rabbit BMSCs}

The stemness of the BMSCs was examined by colony formation, multi-differentiation potential, and stem cell marker expression. The colony formation was examined by a microscope during the primary culture, and the formed colony was stained with methyl violet. The multi-differentiation potential of rabbit BMSCs was tested with adipogenesis, osteogenesis, and chondrogenesis. Briefly, the BMSCs at passage 1 were seeded in a 24 -well plate at a density of $6 \times 10^{4} /$ well in basic medium (10\% heated inactivated FBS, $100 \mathrm{U} / \mathrm{ml}$ of penicillin and $100 \mu \mathrm{g} / \mathrm{ml}$ of streptomycin in DMEM-low glucose) for 2 days. From the third day, some cells were still cultured with basic medium (control) and some cells were cultured either with adipogenic induction medium (Millipore, Cat. \#SCR026, Billerica, MA, USA) for adipogenesis, or with osteogenic differentiation induction medium (Millipore, Cat. \#SCR028, Billerica, CA, USA) for osteogenesis, or with chondrogenic induction medium (ThermoFisher, Cat. A1007101, Waltham, MA, USA) for chondrogenesis. After 3 weeks of culture, the adipogenesis

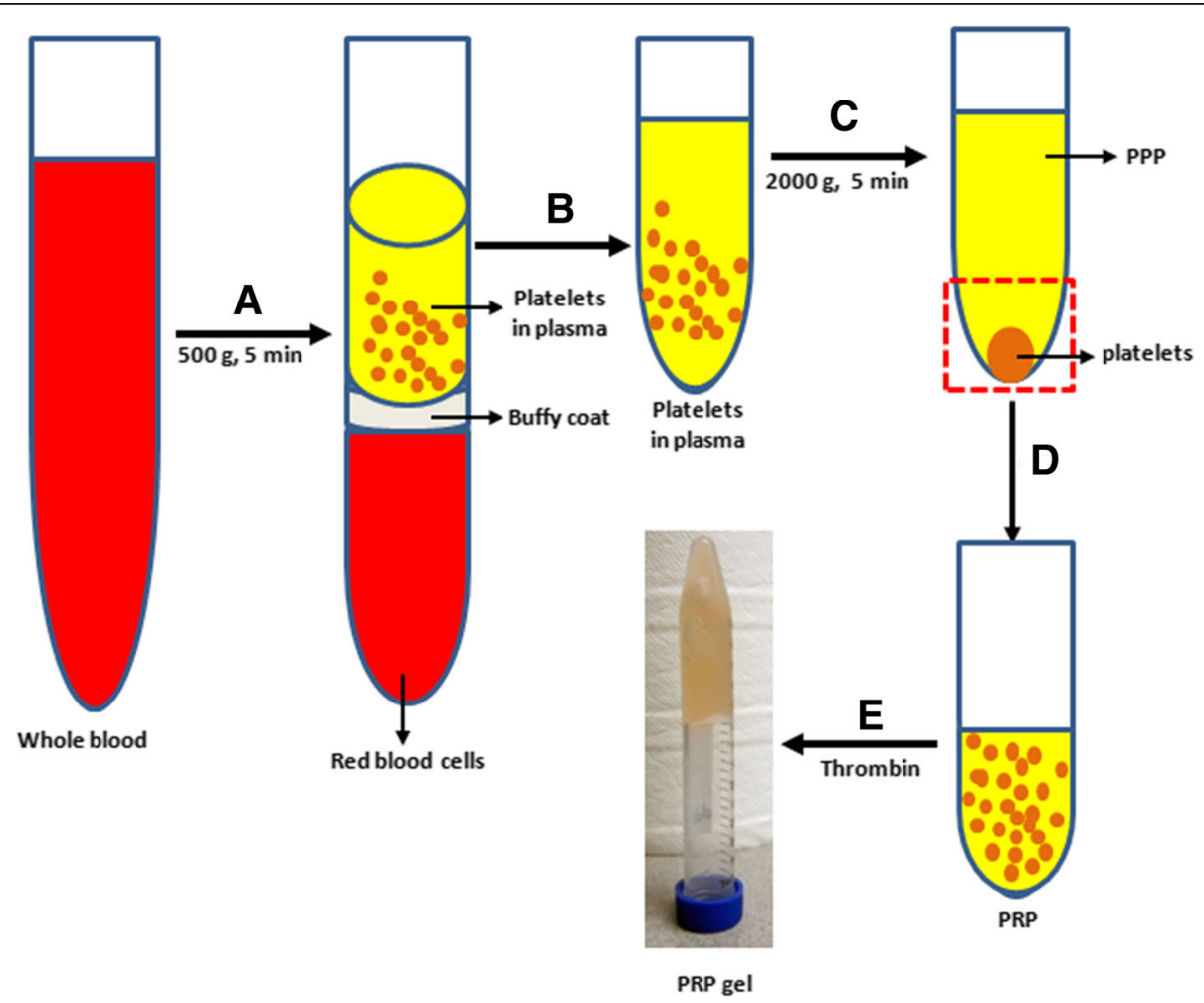

Fig. 1 Preparation of platelet-rich plasma (PRP) from the whole blood by five steps. (a) Whole blood was separated into three layers by a centrifuge at $500 \mathrm{~g}$ for $5 \mathrm{~min}$. (b) The platelet-containing plasma (top layer) was transferred into a new centrifuge tube. (c) The platelet pallet was obtained by a centrifuge at $2000 \mathrm{~g}$ for $5 \mathrm{~min}$. (d) The PRP was prepared by suspending platelets with PPP. (e) The PRP gel was obtained by adding thrombin into PRP solution 
was tested by oil red $\mathrm{O}$ staining, the osteogenesis was determined by alizarin red $\mathrm{S}$ staining, and chondrogenesis was tested by safranin $\mathrm{O}$, alcian blue, and toluidine blue staining.

The stemness of the BMSCs was further tested by immunostaining on four stem cell markers: nucleostemin, stro-1, CD44, and CD90. The BMSCs at passage 1 were seeded in 12-well plates at the density of $3 \times 10^{4} /$ well and cultured with growth medium for 3 days. The cells were washed once with PBS fixed with $4 \%$ paraformaldehyde in PBS for $30 \mathrm{~min}$ at room temperature. For nucleostemin testing, the fixed cells were further treated with $0.1 \%$ Triton X-100 for $30 \mathrm{~min}$ and washed three times with PBS. The treated cells were incubated with goat anti-nucleostemin antibody (1:400, Neuromics, Cat. \#GT15050, Edina, MN) at room temperature for $2 \mathrm{~h}$. The cells were washed with PBS for three times and reacted with $\mathrm{Cy}$-3-conjugated donkey anti-goat IgG antibody (1:500, Millipore, Cat. \#AP180C, Billerica, MA) at room temperature for $1 \mathrm{~h}$ for nucleostemin testing.

For stro-1, CD44, and CD90 staining, the fixed cells were incubated either with mouse anti-stro-1 antibody (1:400, Invitrogen, Cat. \#398401, Frederick, MD), or with rat anti-CD44 antibody (1:500, LifeSpan BioScience, Cat. LS-C13434-100, Seattle, WA, USA), or with mouse antiCD90 antibody (1:400, antibodies online.com, Cat. \#ABIN2472805) at room temperature for $2 \mathrm{~h}$, and washed three times with PBS. The washed cells were reacted either with Cy3-conjugated goat anti-mouse IgG antibody (1:500, Millipore, Cat. \#AP124C, Billerica MA) at room temperature for $1 \mathrm{~h}$ to test stro-1 and CD90 expression or with cy-3 conjugated goat anti-rat IgG antibody at room temperature for $1 \mathrm{~h}$ for CD44 testing.

The positively stained cells were examined under an inverted fluorescent microscope (Nikon Eclipse, TE2000-U) and analyzed by semi-quantification using SPOT $^{\mathrm{TM}}$ imaging software (Diagnostic Instruments Inc., Sterling Heights, MI). Five views were taken from each well, and a total of 15 views from three wells were selected for each stem cell marker testing. The percentage of each stem cell marker expression was obtained by dividing the number of positively stained cells by the total number of the cells stained by the nuclear staining reagent Hoechst fluorochrome $33342(1 \mu \mathrm{g} / \mathrm{ml}$; Sigma, St. Louis, MO).

\section{Effect of KGN on chondrogenic differentiation of BMSCs in vitro}

The KGN effect on chondrogenic differentiation of BMSCs was tested in vitro according to the published protocol [18]. The rabbit BMSCs were seeded with 0.5 $\mathrm{ml}$ of growth medium in 24-well plates at a density of $6 \times 10^{5} /$ well and centrifuged at $1500 \mathrm{~g}$ for $5 \mathrm{~min}$, and the formed cell pellet in each well was incubated overnight at $37^{\circ} \mathrm{C}$ with $5 \% \mathrm{CO}_{2}$. In the next morning, the medium was carefully removed, and the cell pallets were cultured with various concentrations of $\mathrm{KGN}$-containing media $(0,10,100,1000 \mathrm{nM})$ for 2 weeks. The medium was changed every 3 days. At day 14, the cells were fixed with $70 \%$ ethanol in an ice bath for $1 \mathrm{~h}$ and washed with distilled water three times. The cells were then stained either with safranin $\mathrm{O}$, or alcian blue, or toluidine blue for $1 \mathrm{~h}$ at room temperature according to the standard protocols. The stained cells were observed under an inverted microscope (Nikon Eclipse, TE2000-U), and a charge-coupled device camera was used to capture images and analyzed by imaging software (Diagnostic Instruments Inc., Sterling Heights, MI).

\section{Quantitative real-time RT-PCR for genetic analysis of BMSCs}

The effect of KGN on chondrogenic differentiation of rabbit BMSCs was further analyzed by quantitative realtime reverse transcriptase-polymerase chain reaction (qRT-PCR) according to the published protocol [18]. After 2 weeks of culture with varying concentrations of $\mathrm{KGN}$, the RNA was extracted from the BMSCs by using RNeasy Mini Kit (Qiagen). The gene expression in BMSCs was tested by two steps. At the first step, a total of $1 \mu \mathrm{g}$ of RNA was used for first-strand cDNA synthesis by reverse transcription kit (Invitrogen). The synthesis of cDNA was performed at $65^{\circ} \mathrm{C}$ for 5 min with cooling for $1 \mathrm{~min}$ at $4{ }^{\circ} \mathrm{C}$, then $42{ }^{\circ} \mathrm{C}$ for $50 \mathrm{~min}$ and $72{ }^{\circ} \mathrm{C}$ for 15 $\mathrm{min}$. At the second step, two chondrocyte-related genes, collagen type II and Sox-9, were tested by qRT-PCR using Qiagen QuantiTect SYBR Green PCR Kit (Qiagen) in a real-time PCR system (Step One Plus; AB Applied Biosystems). Glyceraldehyde-3-phosphate dehydrogenase (GADPH) was used as an internal control and the sequence. Rabbit-specific primers were designed according to the published method [28], and the sequences were listed as follows: 5'-TGG GTG TTC TAT TTA TTT ATT GTC TTC CT-3' was used for collagen II (forward), 5'-GCG TTG GAC TCA CAC CAG TTA GT-3' was used for collagen II (reverse); 5'-AGT ACC CGC ACC TGC ACA AC-3' was used for SOX-9 (forward), 5'-CGC TTC TCG CTC TCG TTC AG-3' was used for SOX-9 (reverse); 5'-ACT TTG TGA AGC TCA TTT CCT GGT A-3' was used for GAPDH (forward), and 5' GTG GTT TGA GGG CTC TTA CTC CTT-3' was used for GAPDH (reverse). The PCR was performed for 50 cycles after an initial denaturation at $95^{\circ} \mathrm{C}$ for $2 \mathrm{~min}$. Each cycle needed a denaturation for $50 \mathrm{~s}$ at $95^{\circ} \mathrm{C}$ with subsequent annealing for $50 \mathrm{~s}$ at $57^{\circ} \mathrm{C}$ and extension for $40 \mathrm{~s}$ at $72{ }^{\circ} \mathrm{C}$, and PCR reaction was terminated at $70{ }^{\circ} \mathrm{C}$ after a 10-min extension. Three independent experiments were performed to obtain a relative level of expression of the genes. 


\section{In vivo meniscus repair experiment}

Fifteen New Zealand white rabbits (6 months old, female) were used for in vivo experiment. The rabbits were anesthetized, and three holes were created in each meniscus using a biopsy punch ( $1 \mathrm{~mm}$ of diameter/hole). The rabbits were divided into five groups with three rabbits/ group: the wounds in the saline group were treated with $20 \mu \mathrm{l}$ of saline (saline); the wounds in the KGN group were treated with $5 \mu \mathrm{l}$ of $100 \mathrm{mM} \mathrm{KGN}$ and $15 \mu \mathrm{l}$ saline (KGN); the wounds in the KGN+PRP group were treated with $5 \mu \mathrm{l}$ of $100 \mathrm{mM} \mathrm{KGN}, 5 \mu \mathrm{l}$ of 10,000 U/ ml thrombin, and $10 \mu \mathrm{l}$ of PRP (KGN+PRP); the wounds in the BMSC+PRP group were treated with 10,000 BMSCs in $10 \mu \mathrm{l}$ of PRP, $5 \mu \mathrm{l}$ of saline, and $5 \mu \mathrm{l}$ of $10,000 \mathrm{U} / \mathrm{ml}$ thrombin (PRP+BMSC); the wounds in the $\mathrm{KGN}+\mathrm{PRP}+\mathrm{BMSC}$ group were treated

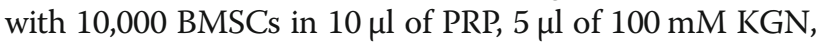
and $5 \mu \mathrm{l}$ of $10,000 \mathrm{U} / \mathrm{ml}$ thrombin (KGN+PRP+BMSC). The menisci were collected at day 90 post-surgery for gross inspection and histochemical analysis.

\section{Histological analysis}

At day 90 after surgery, menisci were harvested and placed in a pre-labeled base mold filled with frozen section medium (Neg 50; Richard-Allan Scientific; Kalamazoo, MI). The base mold with tissue samples was quickly immersed in liquid nitrogen cold 2-methylbutane and allowed to solidify completely. The tissue blocks were then either placed on dry ice and subsequently stored in a deep freezer $\left(-80^{\circ} \mathrm{C}\right)$ until used for histological analysis or cut into $10-\mu \mathrm{m}$-thick sections, which were fixed with $4 \%$ paraformaldehyde for $30 \mathrm{~min}$. The fixed tissue sections were stained with either hematoxylin and eosin $(\mathrm{H} \& \mathrm{E})$ or safranin $\mathrm{O}$ and fast green according to standard protocols.

\section{Statistical data analysis}

One-way ANOVA was used, then followed by Fisher's PLSD test for multiple comparisons. When $P$ values are less than 0.05 , the two groups compared are considered to be significantly different.

\section{Results}

Both in vitro and in vivo experiments first required the isolation of BMSCs from rabbit femur bones, and the stemness of these BMSCs was confirmed by colony formation, multi-differentiation potential, and stem cell marker expression. The results showed that the cells isolated from rabbit femur bone started the colony formation at day 3 of the primary culture (Fig. 2a) and the size of the colony increased during the culture (Fig. 2b, c). The methyl violet staining indicated that the colonies formed by rabbit BMSCs were heterogeneous (Fig. 2d-g). The most of BMSCs either were cobblestone shape (black arrows in Fig. 2c) or spindle shape (red arrows in Fig. 2e).
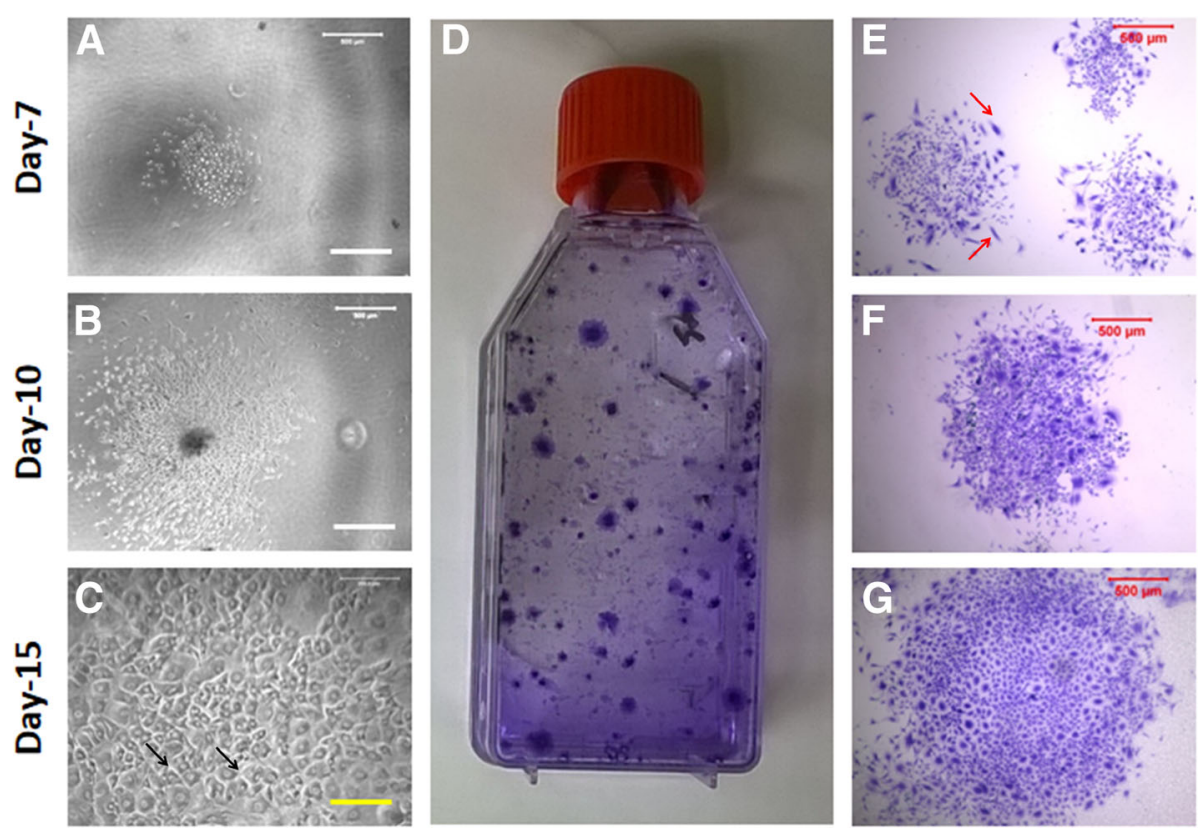

Fig. 2 Colony formation of the BMSCs during primary culture. a A typical colony was formed at day 7. b A typical colony was formed at day 10. $\mathbf{c}$ A typical colony was formed at day 10. $\mathbf{d}-\mathbf{g}$ The colonies were formed at day 15 and stained with methyl violet. The colonies formed by the BMSCs were heterogeneous as evidenced by cell shape and colony size $(\mathbf{d}-\mathbf{g})$. Some colonies were formed by cobblestone-like cells (black arrows in $\mathbf{c}$ ), and some colonies were formed by spindle-like cells (red arrows in $\mathbf{e}$ ) 
Immunostaining indicated the cells isolated from the rabbit femur bones were stem cells as evidenced by more than $90 \%$ of BMSCs expressed nucleostemin (Fig. 3a-c, m), more than $63.43 \%$ of BMSCs expressed stro-1 (Fig. 3d-f, m), more than $78 \%$ of BMSCs were positively stained by CD44 (Fig. $3 \mathrm{~g}-\mathrm{i}, \mathrm{m}$ ), and more than $96 \%$ of BMSCs were positively stained with CD90 (Fig. 3j-l, m).

Further studies demonstrated that the cells isolated from rabbit bone marrow had multi-differentiation potential. After the BMSCs were cultured with various differentiation media for 3 weeks, they were positively stained either by oil red $\mathrm{O}$ (Fig. 4c, d), or by alizarin red $\mathrm{S}$ (Fig. $4 \mathrm{~g}-\mathrm{h}$ ), or by safranin $\mathrm{O}$ (Fig. $4 \mathrm{k}-\mathrm{l}$ ) - Lower percentages of the BMSCs grown in basic medium (control) were positively stained either with oil red $\mathrm{O}$ (Fig. 4a, b), or with alizarin red S (Fig. 4e, f), or with safranin $O$ (Fig. $4 i, j$ ). These results indicated that the cells isolated from rabbit bone marrow were BMSCs and can be used for the following experiments.
More results showed that KGN induced the chondrogenetic differentiation of the BMSCs in a concentrationdependent manner (Fig. 5). The proteoglycan expression was increased in KGN-treated BMSCs as evidenced by three different chondrocyte staining reagents alcian blue (Fig. 5a-e), safranin $\mathrm{O}$ (Fig. 5f-j), and toluidine blue (Fig. 5k-t). The KGN-treated BMSCs also changed their morphology from spindle shape (black arrows in Fig. 5p) to round shape (yellow arrows, Fig. 5q-t) when they were cultured with KGN-containing medium. The qRT-PCR results indicated the upregulation of two chondrocyte-related genes, collagen II and SOX-9, found in the BMSCs cultured with KGN-containing medium in a concentrationdependent manner (Fig. $5 \mathrm{u}$ ).

Based on the above experimental results, we investigated the combination effect of BMSC-containing KGN-PRP gel on wounded meniscus healing using an in vivo rabbit model. Segregation of rabbits into 5 groups was done, and three holes were created in each rabbit meniscus by a biopsy punch (Fig. 6a, b). These wounded menisci were given different treatments
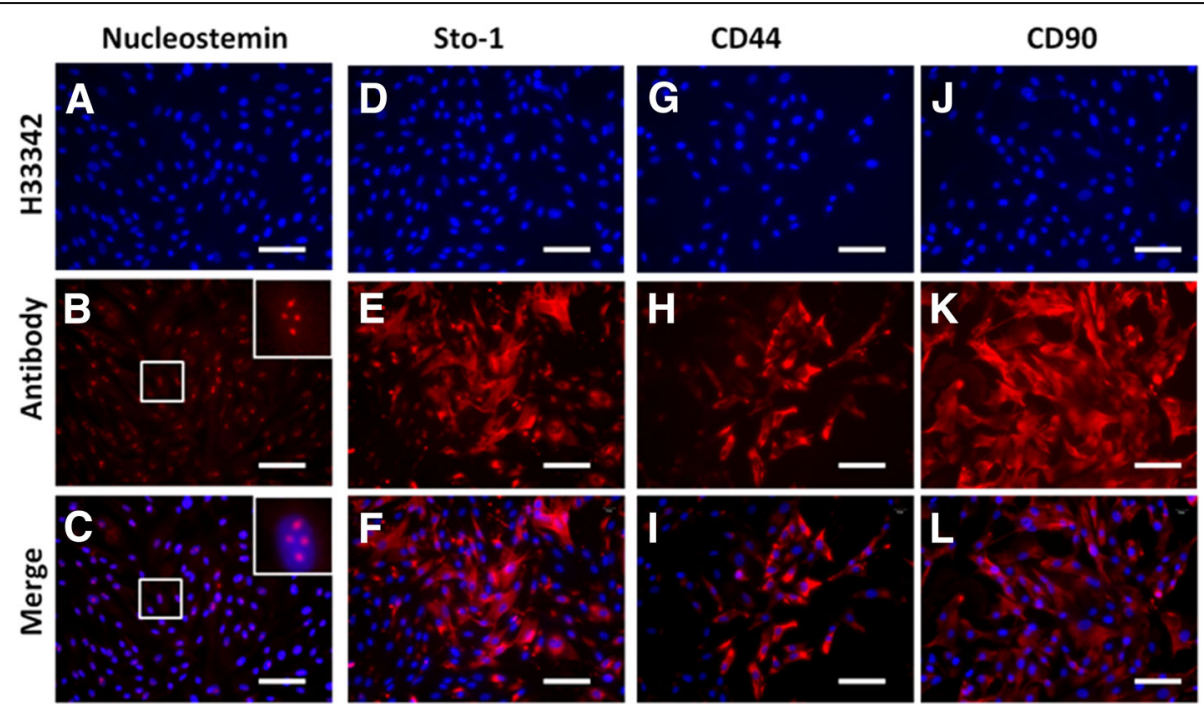

M

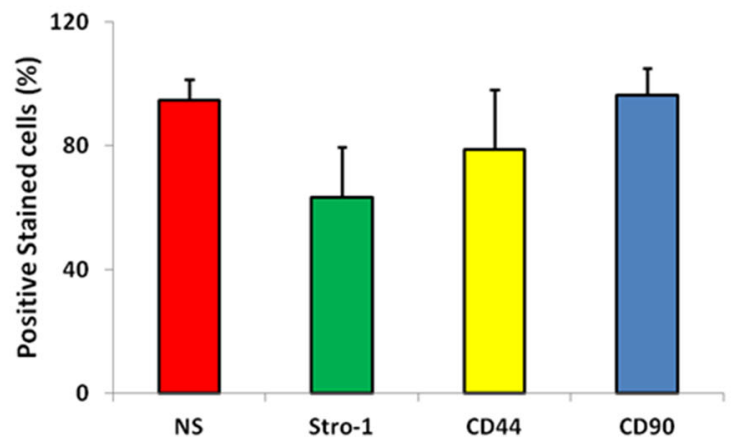

Fig. 3 Stem cell marker expression in the BMSCs examined by immunostaining. $\mathbf{a}-\mathbf{c}$ The cells were stained with nucleostemin. $\mathbf{d}-\mathbf{f}$ The cells were stained with stro-1. $\mathbf{g}-\mathbf{i}$ The cells were stained with CD44. $\mathbf{j}-\mathbf{I}$ The cells were stained with CD90. $\mathbf{a}, \mathbf{d}, \mathbf{g}, \mathbf{j}$ The cells were stained with H33342. $\mathbf{b}$, e $\mathbf{h}, \mathbf{k}$ The cells were stained with the antibodies. $\mathbf{c}, \mathbf{f}, \mathbf{i}, \mathbf{I}$ The images were merged images by $\mathbf{a}, \mathbf{d}, \mathbf{g}, \mathbf{j}$, and $\mathbf{b}, \mathbf{e}, \mathbf{h}, \mathbf{k}$. $\mathbf{m}$ The semi-quantification of positively stained cells by each stem cell marker. The insert images were enlarged box areas in the images of $\mathbf{b}$ and $\mathbf{c}$. Bars $100 \mu \mathrm{m}$ 


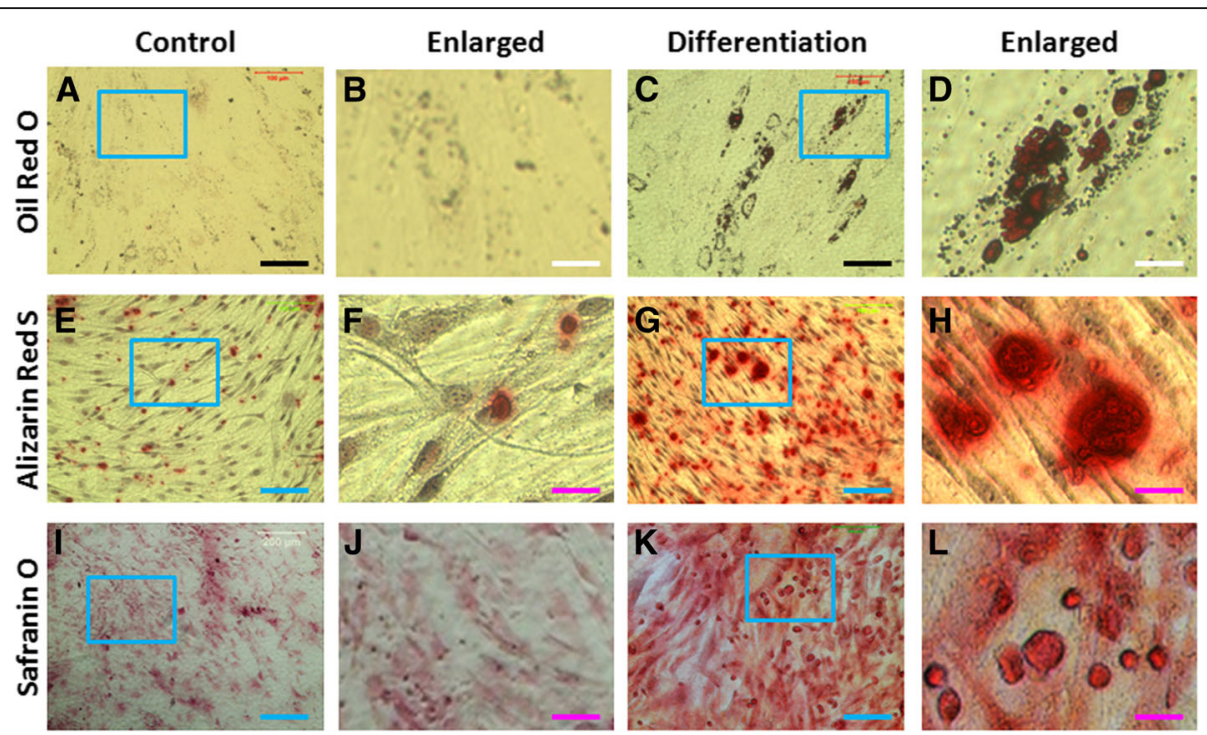

Fig. 4 Multi-differentiation potential of the BMSCs cultured with various differentiation media for 3 weeks. $\mathbf{a}$, $\mathbf{b}$ The cells were cultured with basic medium for 3 weeks and stained with oil red O. c, d The cells were cultured with adipogenic differentiation medium for 3 weeks and stained with oil red O. e, $\mathbf{f}$ The cells were cultured with basic medium for 3 weeks and stained with alizarin red S. $\mathbf{g}, \mathbf{h}$ The cells were cultured with osteogenic differentiation medium for 3 weeks and stained with alizarin red S. $\mathbf{i}, \mathbf{j}$ The cells were cultured with basic medium for 3 weeks and stained with Safranin O. k, I The cells were cultured with chondrogenic differentiation medium for 3 weeks and stained with Safranin O. Black bars $100 \mu \mathrm{m}$; white bars $20 \mu \mathrm{m}$; blue bars $200 \mu \mathrm{m}$; pink bars $40 \mu \mathrm{m}$

namely saline (Fig. 6c), KGN (Fig. 6d), KGN+PRP (Fig. 6e), PRP+BMSC (Fig. 6f), and BMSC+KGN+PRP (Fig. 6g). Gross view of the meniscus at day 90 post treatments showed large unhealed wounded areas in the meniscus treated with saline (red arrows in Fig. 6h) and KGN (red arrow in Fig. 6i). The wounds healed to a good extent in the third group treated with $\mathrm{KGN}+\mathrm{PRP}$, but the meniscus tissue formed was thinner (green arrow in Fig. 6j) in comparison with the fourth group (Fig. 6k) and the fifth group (Fig. 61). No unhealed wound areas were found in the meniscus treated either with BMSC+PRP (Fig. 6k) or with $\mathrm{BMSC}+\mathrm{KGN}+\mathrm{PRP}$ (Fig. 6l), and the new formed tissue was in normal thickness and healthy (Fig. 6k, l).

In addition, histochemical staining of the meniscus with $\mathrm{H} \& \mathrm{E}$ staining after BMSCs-containing KGN-PRP gel treatment (BMSCs+KGN+PRP) for 3 months showed the meniscus healed well and led to the formation of fibrocartilage-like tissue (Fig. 7q-t). Although the wounds treated with BMSCs-containing PRP gel healed completely, more collagen fiber-like tissues were found in the wound areas (Fig. $7 \mathrm{~m}-\mathrm{p}$ ) than the wounds treated with BMSCs-containing KGN-PRP gel (Fig. 7q-t). There were large gaps found in the wound areas treated either with saline (Fig. 7a-d) or with KGN (Fig. 7e-h). Although the wounds were healed with $K G N+P R P$ gel treatment (Fig. 7i-l), new formed tissue was thinner than the around tissues of the wound area (Fig. 7i-l). Furthermore, no cartilage-like tissue was found in the wound area treated with saline (Fig. $7 \mathrm{a}-\mathrm{d}$ ). These results were further demonstrated by safranin $\mathrm{O}$ and fast green staining (Fig. 8). The wound area treated with BMSCs+KGN+PRP was completely filled with fibrocartilage-like tissue as evidenced by positively stained cells with safranin $\mathrm{O}$ and fast green (red in Fig. 8q-t). Although the wounds treated with BMSCs-containing PRP gel (Fig. $8 \mathrm{~m}-\mathrm{p}$ ) healed much better than the wounds treated either with saline (Fig. 8a-d) or with KGN+PRP gel (Fig. 8i-l), more collagen fiber-like tissues with less cartilage-like tissues were found in the wound areas treated with BMSCs-containing PRP gel (Fig. 8m-p) than the wounds treated with BMSCs-containing KGNPRP gel (Fig. 8q-t). There were large unhealed wound areas that existed in the wounds treated either with saline (Fig. 8a-d) and KGN (Fig. 8e-h). The wounds treated with KGN+PRP showed some fibrocartilage-like tissues which were weakly stained with safranin $\mathrm{O}$ and fast green (Fig. 8i-l).

\section{Discussion}

The aim of this study was to develop a novel bioactive scaffold for wounded meniscus healing. It is believed that such a scaffold should be structurally capable of supporting cell growth, promoting cell proliferation, enhancing vascularization, and inducing stem cell chondrogenic differentiation. To reach this aim, we developed this new bioactive scaffold using a rabbit BMSCscontaining KGN-PRP gel. Based on analysis and a thorough literature review on BMSCs and meniscal healing 


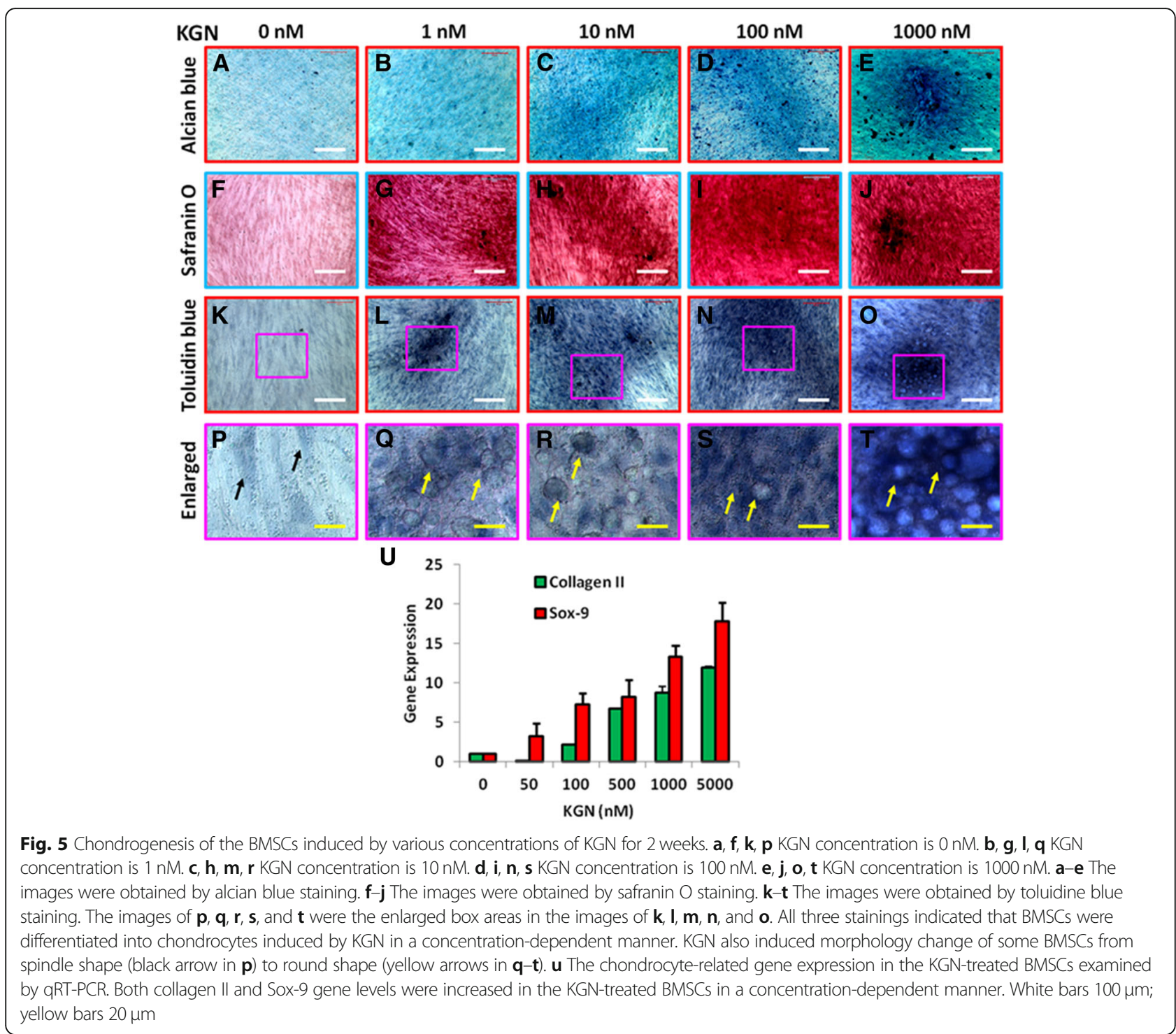

[17-20, 29, 30], we derived a hypothesis stating that BMSCs can form meniscus-like tissue when treated with KGN+PRP gel because (1) BMSCs when treated with KGN can proliferate and differentiate into chondrocytes in vitro and (2) treatment of BMSCs with KGN+PRP can enhance the healing of injured meniscus in vivo. To test our hypothesis, the experiments were performed using in vitro cell culture model and in vivo rabbit surgery model. The findings of this study established that KGN can induce differentiation of BMSCs into chondrocytes in vitro and form meniscus-like tissue in vivo. This was clearly evident from positive staining of BMSCs by safranin $\mathrm{O}$, alcian blue, and toluidine blue when they were cultured with KGN-containing medium in vitro (Fig. 5), and histological staining of healed meniscus tissue sections by $\mathrm{H} \& \mathrm{E}$ and safranin $\mathrm{O}$ and fast green when the defective meniscus was treated with MSCs-containing KGN-PRP gel in vivo (Figs. 7 and 8 ).

It has been reported that the use of regenerative medicine in the treatment of wound healing can be applied through 1 of 3 main channels: injection of cells, scaffolds, and trophic factors [31]. Our results suggested that all three channels are important for wounded meniscus healing. The previous studies have shown that the BMSCs have a high potential of diverse chondrogenesis with the capacity to exhibit meniscus-like phenotype [32-36]. In the present study, we used rabbit BMSCs to promote defective meniscus regeneration. We found that stem cells play a critical role in wounded meniscus healing. Although a cell-free bioactive scaffold made by KGN and PRP could enhance the wounded meniscus healing, the healed meniscus was thinner than the host tissue (Fig. 6j) and the wounds treated with BMSCs-containing PRP gel (Fig. 6k) 

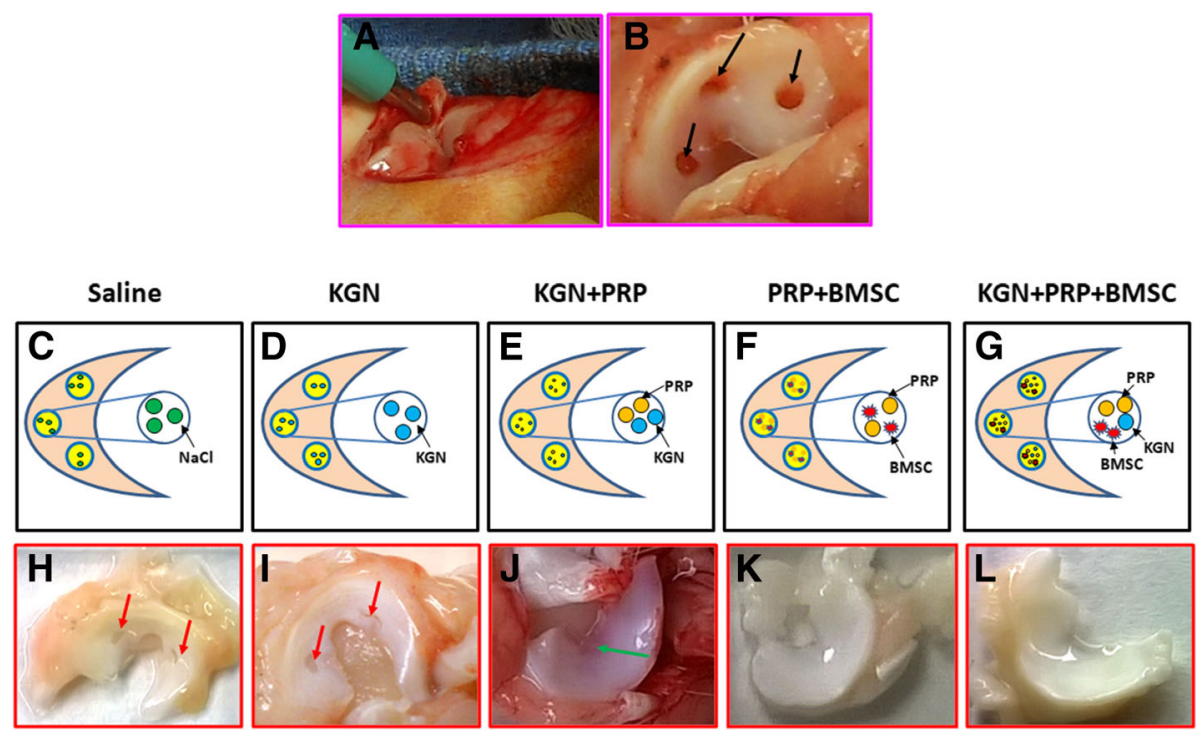

Fig. $6 \mathrm{KGN}$ effect on wounded meniscus healing by an in vivo rabbit model. a A biopsy punch with $1 \mathrm{~mm}$ diameter was used for creating a wound on rabbit meniscus. $\mathbf{b}$ Three holes ( $1 \mathrm{~mm}$ diameter/hole, black arrows in $\mathbf{b}$ ) were created in each meniscus of 12 rabbits by a biopsy punch. c Each wound in three rabbits was treated with $20 \mu \mathrm{l}$ of saline (saline). d Each wound in 3 rabbits was treated with $5 \mu$ l of $100 \mu$ MKGN and $15 \mu \mathrm{l}$ of saline (KGN). e Each wound in 3 rabbits was treated with $5 \mu \mathrm{l}$ of $100 \mu \mathrm{MKGN}$ and $5 \mu \mathrm{l}$ of 10,000 U/ml thrombin and $10 \mu \mathrm{l}$ of PRP (KGN+PRP gel). $\mathbf{f}$ Each wound in 3 rabbits was treated with $5 \mu \mathrm{l}$ of saline, $5 \mu \mathrm{l}$ of 10,000 U/ml thrombin, $10 \mu \mathrm{l}$ of PRP, and 10,000 BMSCs (PRP+BMSC). $\mathbf{g}$ Each wound in 3 rabbits was treated with $5 \mu$ l of $100 \mu M K G N, 5 \mu l$ of 10,000 U/ml thrombin, $10 \mu l$ of PRP, and 10,000 BMSCs (KGN+PRP+BMSC). $\mathbf{h}$ Gross view of the wounded rabbit meniscus at day 90 post-surgery with saline treatments. $\mathbf{i}$ Gross view of the wounded rabbit meniscus at day 90 post-surgery with KGN treatment. $\mathbf{j}$ Gross view of the wounded rabbit meniscus at day 90 post-surgery with PRP-KGN gel treatment. $\mathbf{k}$ Gross view of the wounded rabbit meniscus at day 90 post-surgery with BMSCs-containing PRP gel treatment. I Gross view of the wounded rabbit meniscus at day 90 post-surgery with BMSCs-containing KGN-PRP gel treatment. Large unhealed wound areas were still found in the saline-treated meniscus (red arrows in $\mathbf{h}$ ) and KGN-treated meniscus (red arrows in i). Although the wounds were healed with KGNPRP gels, the new formed meniscus tissue was thinner (green arrow in $\mathbf{j}$ ) than BMSCs-containing PRP-treated wound (k) and BMSCs-containing KGN-PRP gel-treated wound (I). There was no unhealed wound area found in the meniscus treated with BMSCs-containing PRP gel and BMSCscontaining KGN-PRP gel and the new formed meniscus in both groups was thick and healthy $(\mathbf{k}, \mathbf{I})$

and BMSCs-containing KGN-PRP scaffold (Fig. 6l). Histological results showed that much less cartilage-like cells formed in the wound area treated with cell-free KGN-PRP scaffold than that formed in the wound areas treated either with BMSCs-containing PRP gel or with BMSCscontaining KGN-PRP scaffold (Figs. 7 and 8).

Our results have demonstrated that BMSCs play an important role in wounded meniscus healing. Our findings indicated that cartilage healing is mediated by bone marrow stem cells (BMSCs) and delivered by blood to the injured meniscus as occurs in other injured tissues [37]. The poor healing of injured meniscus is due to the poor blood supply to the "white-white" zone of the meniscus so the bone marrow-derived stem cells (BMSCs) fail to reach the injured meniscus resulting in its poor healing. To enhance the wounded meniscus healing, we delivered BMSCs within a PRP scaffold to ensure that the BMSCs could stay in the site of injury, and the fibrin of the PRP acts as a provisional matrix for cell proliferation and differentiation. It has been reported that the mesenchymal stem cells (MSCs) and bone marrow- mononuclear cells (BM-MNCs) are two important cell types used in cellular therapy. Since both have the same origin and pathway homing at the site of injury, the MSCs and BM-MNCs may belong to the same differentiation line, may have common cellular features and functions, and may have similar therapeutic efficacy. These cells have been shown to accelerate and promote the healing of various tissue injuries in animal and human studies [38]. Our results suggested that the treatment of BMSCs-containing KGN+PRP scaffold is a good approach for promoting the wounded meniscus healing.

Our results also indicated that in the healing process, some bioactive reagent, such as KGN is more important for cell proliferation and chondrogenic differentiation. Kartogenin is a small heterocyclic compound discovered recently, which is known to induce chondrogenic differentiation of BMSCs via core binding factor $\beta(\mathrm{CBF} \beta)$-runt-related transcription factor 1 (Runx1) pathway [17]. It has been reported that KGN was effectively used in repairing the damaged articular cartilage in mice with osteoarthritis [17]. Our results 


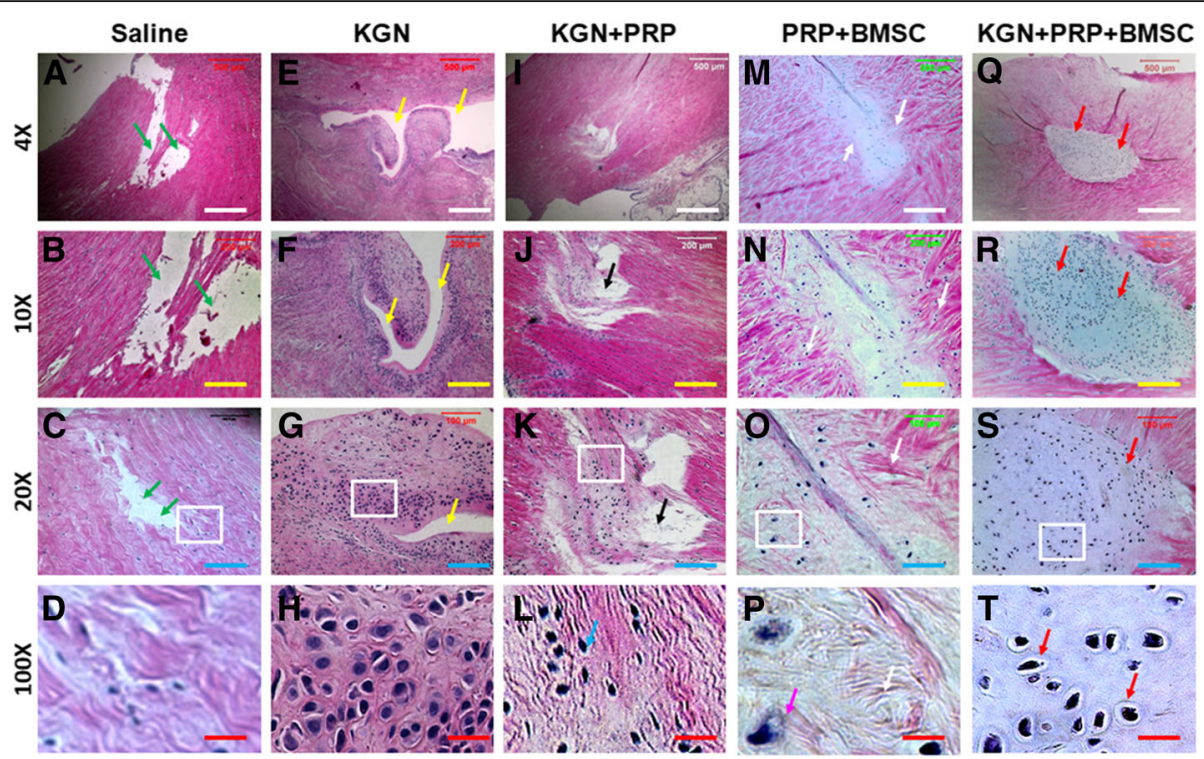

Fig. 7 H\&E staining of rabbit menisci after five different treatments for 3 months. a-d The wounded meniscus treated with saline at day 90 post-surgery. $\mathbf{e}-\mathbf{h}$ The wounded meniscus treated with KGN at day 90 post-surgery. $\mathbf{i}-\mathbf{I}$ The wounded meniscus treated with KGN-PRP gel at day 90 post-surgery. $\mathbf{m}-\mathbf{p}$ The wounded meniscus treated with BMSCs-containing PRP gel at day 90 post-surgery. q-t The wounded meniscus treated with BMSCs-containing KGN-PRP gel at day 90 post-surgery. The images of $\mathbf{d}, \mathbf{h}, \mathbf{I}, \mathbf{p}$, and $\mathbf{t}$ were enlarged box areas in the images of $\mathbf{c}, \mathbf{g}, \mathbf{k}, \mathbf{o}$, and $\mathbf{s}$, respectively. Large unhealed wound areas were still found in the saline-treated meniscus (green arrows in $\mathbf{a}, \mathbf{b}, \mathbf{c}$ ) and KGN-treated meniscus (yellow arrows in $\mathbf{e}, \mathbf{f}, \mathbf{g}$ ). Although the wounds were healed with KGN-PRP gels, new formed tissues were thinner than around tissues (black arrow in $\mathbf{i}, \mathbf{j}, \mathbf{k}$ ) and less cells in the new formed tissues were fibrocartilage-like cells (blue arrow in $\mathbf{I}$ ) than the wounds treated with BMSCs-containing PRP gel $(\mathbf{m}-\mathbf{p})$ and BMSCs-containing KGN-PRP gel (q-t). There was no unhealed wound area found in the meniscus treated with BMSCs-containing PRP gel (m- $\mathbf{p})$ and BMSCs-containing KGN-PRP gel $(\mathbf{q}-\mathbf{t})$; however, the regenerated tissues were different in the wound areas treated with two different BMSCs-containing PRP gels. More collagen fiber-like tissues were found in the wound treated with BMSCs-containing PRP gel (white arrows in $\mathbf{m}-\mathbf{p}$ ), while more cartilagelike cells were found in the wound treated with BMSCs-containing KGN-PRP gel (red arrows in $\mathbf{q}-\mathbf{t}$ ). White bars $500 \mu \mathrm{m}$; yellow bars $200 \mu \mathrm{m}$; blue bars $100 \mu \mathrm{m}$; red bars $20 \mu \mathrm{m}$

showed that large unhealed wound area was presented in the defective meniscus without KGN treatment (Figs. 6 7, and 8).

Moreover, our findings told that only KGN treatment without a carrier/scaffold was not good enough to enhance the wounded meniscus healing as evidenced by large unhealed wound areas found in KGN-treated wounded meniscus due to KGN flowing out (Figs. 6, 7, and 8). We found that the injection of KGN directly into the wound area could not keep enough concentration of KGN for wounded meniscus healing. In order to increase the efficacy of KGN treatment and avoid KGN flowing out, we used PRP gel as a KGN carrier. It is well known that PRP is a concentrated blood derivative that has been used to augment tissue healing in combination with tissue engineering modalities including BMSCs and tendon stem cells [39]. It stimulates chondrocytes to form cartilaginous tissue and enhance repair of meniscus defects [40]. In the present study, PRP gel not only carried the KGN in the wound area, but also enhanced the wounded meniscus healing by releasing some growth factors when the gel formation by adding bovine thrombin into the mixture of rabbit
BMSCs, KGN, and PRP. Recent studies showed that PRP alone cannot effectively produce fibrocartilage zone $[29,30]$. Our results also found that to achieve augmented results PRP should be combined with biocompounds like KGN.

The first limitation of this study includes involvement of only 15 rabbits and we did not test BMSCs only group, PRP only group, and $\mathrm{KGN}+\mathrm{BMSCs}$ group. In our future study, we will use more rabbits to complete these experiments including healing mechanism study and long-term benefits of KGN+PRP treatment. Secondly, the mechanical properties of the new formed meniscus were not tested; hence, future studies will focus on investigating the mechanical aspects of the regenerated meniscus. Thirdly, in the current study, we only used one ratio of KGN and PRP to treat the wounded meniscus, the regenerated tissue contained less collagen fibers than the normal fibrocartilage found in the rabbit meniscus. The previous study has shown that the concentration of PRP is important for tissue regeneration [41]. The future study will investigate the effect of different concentrations of KGN and PRP on fibrocartilage formation. 

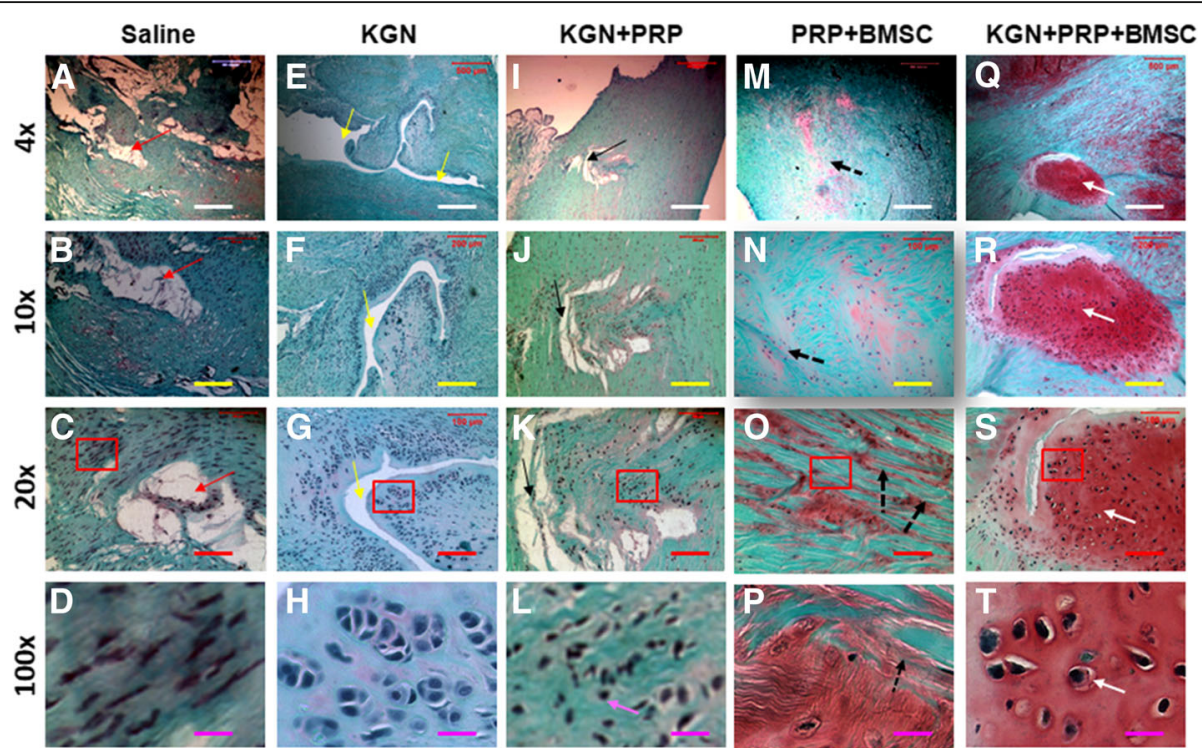

Fig. 8 Safranin $\mathrm{O}$ and fast green staining of rabbit menisci after five different treatments for 3 months. a-d The wounded meniscus treated with saline at day 90 post-surgery. $\mathbf{e}-\mathbf{h}$ The wounded meniscus treated with KGN at day 90 post-surgery. $\mathbf{i}-\mathbf{I}$ The wounded meniscus treated with KGN-PRP gel at day 90 post-surgery. $\mathbf{m}-\mathbf{p}$ The wounded meniscus treated with BMSCs-containing PRP gel at day 90 post-surgery. q-t The wounded meniscus treated with BMSC-containing KGN-PRP gel at day 90 post-surgery. The images of $\mathbf{d}, \mathbf{h}, \mathbf{I}, \mathbf{p}$, and $\mathbf{t}$ were enlarged box areas in the images of $\mathbf{c}, \mathbf{g}, \mathbf{k}, \mathbf{o}$, and $\mathbf{s}$, respectively. Large unhealed wound areas were still found in the saline-treated meniscus (red arrows in $\mathbf{a}-\mathbf{c}$ ) and KGN-treated meniscus (yellow arrows in $\mathbf{e}-\mathbf{g}$ ). Although the wounds were healed with KGN-PRP gels, new formed tissues were thinner than around tissues (black arrows in $\mathbf{i}-\mathbf{k}$ ) and less cells in new formed tissues were fibrocartilage-like cells (pink arrow in $\mathbf{I}$ ) than the wounds treated either with BMSCs-containing PRP gel ( $\mathbf{m}-\mathbf{p})$ or with BMSCs-containing KGN-PRP gels (q-t). There was no unhealed wound area found in the meniscus treated either with BMSCs-containing PRP gel or with BMSCs-containing KGN-PRP gel, but the new formed tissues in these two groups were different, more collagen fiber-like tissues were found in PRP-BMSC-treated meniscus (black dash arrows in $\mathbf{m}$ - $\mathbf{p}$ ), and more cartilage-like cells were found in the wound area treated with BMSCs-containing KGN-PRP gel (white arrows in $\mathbf{q}-\mathbf{t}$ )

\section{Conclusion}

Our findings indicate that KGN induces the differentiation of BMSCs into cartilage-like tissue in vitro and in vivo. Using PRP as a KGN and BMSC carrier promotes cartilage formation. Furthermore, the combination of BMSCs with KGN+PRP gel significantly enhanced cartilage-like tissue formation. Hence, we suggest that BMSCscontaining $\mathrm{KGN}+\mathrm{PRP}$ gel may be used to accelerate and augment the repair of injured menisci in a clinical setting.

\footnotetext{
Abbreviations

BMSC: Bone marrow-derived stem cell; CBF $\beta$ : Core binding factor $\beta$; GADPH: Glyceraldehyde-3-phosphate dehydrogenase; H\&E: Hematoxylin and eosin; KGN: Kartogenin; MSC: Mesenchymal stem cell; PBS: Phosphatebuffered saline; PDGF: Platelet-derived growth factor; PDT: Population doubling time; PPP: Platelet-poor plasma; PRP: Platelet-rich plasma; Runx1: Runt-related transcription factor 1; SC: Sodium citrate; SSEA-4: Stagespecific embryonic antigen 4; TGF: Transforming growth factor;

VEGF: Vascular endothelial growth factor
}

\section{Acknowledgements}

We would like to thank Dr. Mohammad Ahmad Kamal Aboudi for assistance in revising the manuscript.

\section{Authors' contributions}

FL performed the key experiments, analyzed the data, and prepared the manuscript. HX conducted part of the experiments and wrote the manuscript. $\mathrm{HH}$ conceived the project, designed the experiments, and revised the manuscript. All authors read and approved the final manuscript.

\section{Funding}

This work was financially supported by the National Natural Science Foundation of Jiangsu Province (No. BK20161111) and the Nanjing Science and Technology Commission (No. 201605080).

\section{Availability of data and materials}

For data requests, please contact the author.

\section{Ethics approval and consent to participate}

All experimental procedures were approved by the Institutional Animal Care and Use Committee (IACUC) of Nanjing Medical University (Approval number NMU-2015-082) and met requirements described in the National Institute of Health Guide for the Care and Use of Laboratory.

\section{Consent for publication}

Not applicable for consent for publication, because no individuals' data were reported (including individual details, images, or videos) in this study.

\section{Competing interests}

The authors declare that they have no competing interests.

\section{Author details}

'Department of Orthopaedics, The First Affiliated Hospital with Nanjing Medical University, 300 Guangzhou Road, Nanjing 210029, Jiangsu, China. ${ }^{2}$ Department of Sports Medicine and Joint Surgery, Nanjing First Hospital, Nanjing Medical University, 68 Changle Road, Nanjing 210006, Jiangsu, China. ${ }^{3}$ China Orthopaedic Regeneration Medicine Group, Zhejiang 310000,

Hangzhou, China. 
Received: 19 December 2018 Revised: 10 June 2019

Accepted: 26 June 2019 Published online: 08 July 2019

\section{References}

1. He M, Li B, Cui X, Jiang B, He Y, Chen Y, O'Neil D, Szymanski P, Ei-Sayed MA, Huang J, et al. Meniscus-assisted solution printing of large-grained perovskite films for high-efficiency solar cells. Nat Commun. 2017;8:16045.

2. Li G, Yin J, Gao J, Cheng TS, Pavlos NJ, Zhang C, Zheng MH. Subchondral bone in osteoarthritis: insight into risk factors and microstructural changes. Arthritis Res Ther. 2013;15(6):223.

3. Zellner J, Pattappa G, Koch M, Lang S, Weber J, Pfeifer CG, Mueller MB, Kujat R, Nerlich M, Angele P. Autologous mesenchymal stem cells or meniscal cells: what is the best cell source for regenerative meniscus treatment in an early osteoarthritis situation? Stem Cell Res Ther. 2017;8(1):225.

4. Makris EA, Hadidi P, Athanasion KA. The knee meniscus: structure-function, pathophysiology, current repair techniques, and prospects for regeneration. Biomaterials. 2011;32(30):7411-31.

5. Sweigart MA, Athanasiou KA. Toward tissue engineering of the knee meniscus. Tissue Eng. 2001;7(2):111-29.

6. Andersson-Molina $\mathrm{H}$, Karlsson $\mathrm{H}$, Rockborn P. Arthroscopic partial and total meniscectomy: a long-term follow-up study with matched controls. Arthroscopy. 2002;18(2):183-9.

7. Lindhorst E, Vail TP, Guilak F, Wang H, Setton LA, Vilim V, Kraus VB. Longitudinal characterization of synovial fluid biomarkers in the canine meniscectomy model of osteoarthritis. J Orthop Res. 2000;18(2):269-80.

8. McAndrews PT, Arnoczky SP. Meniscal repair enhancement techniques. Clin Sports Med. 1996;15(3):499-510.

9. Gelber PE, Verdonk P, Getgood AM, Monllau JC. Meniscal transplantation: state of the art. J ISAKOS. 2017;2(6):339-49.

10. Zaffagnini S, Giordano G, Vascellari A, Bruni D, Neri MP, lacono F, Kon E, Presti ML, Marcacci M. Arthroscopic collagen meniscus implant results at 6 to 8 years follow up. Knee Surg Sports Traumatol Arthrosc. 2007;15(2):175-83.

11. Vrancken AC, Buma P, van Tienen TG. Synthetic meniscus replacement: a review. Int Orthop. 2013;37(2):291-9.

12. Parkinson B, Smith N, Asplin L, Thompson P, Spalding T. Factors predicting meniscal allograft transplantation failure. Orthop J Sports Med. 2016;4(8): 2325967116663185.

13. Yamzon $J$, Kokorowski P, Koh CJ. Stem cells and tissue engineering applications of the genitourinary tract. Pediatr Res. 2008;63(5):472-7.

14. Tabata Y. Biomaterial technology for tissue engineering applications. J R Soc Interface. 2009;6(Suppl 3):S311-24.

15. Buma $P$, Ramrattan NN, van Tienen $T G$, Veth RP. Tissue engineering of the meniscus. Biomaterials. 2004;25(9):1523-32.

16. Angele P, Johnstone B, Kujat R, Zellner J, Nerlich M, Goldberg V, Yoo J. Stem cell based tissue engineering for meniscus repair. J Biomed Mater Res A 2008:85(2):445-55.

17. Johnson K, Zhu S, Tremblay MS, Payette JN, Wang J, Bouchez LC, Meeusen S, Althage A, Cho CY, Wu X, et al. A stem cell-based approach to cartilage repair. Science. 2012;336(6082):717-21.

18. Zhang J, Wang JH. Kartogenin induces cartilage-like tissue formation in tendon-bone junction. Bone Res. 2014;2:14008-18.

19. Liu C, Ma X, Li T, Zhang Q. Kartogenin, transforming growth factor-beta1 and bone morphogenetic protein-7 coordinately enhance lubricin accumulation in bone-derived mesenchymal stem cells. Cell Biol Int. 2015;39(9):1026-35.

20. Huang $\mathrm{H}, \mathrm{Xu} \mathrm{H}$, Zhao J. A novel approach for meniscal regeneration using kartogenin-treated autologous tendon graft. Am J Sports Med. 2017;45(14): 3289-97.

21. Eppley BL, Woodell JE, Higgins J. Platelet quantification and growth factor analysis from platelet-rich plasma: implications for wound healing. Plast Reconstr Surg. 2004;114(6):1502-8.

22. Gogna P, Gaba S, Mukhopadhyay R, Gupta R, Rohilla R, Yadav L. Plantar fasciitis: a randomized comparative study of platelet rich plasma and low dose radiation in sportspersons. Foot (Edinb). 2016;28:16-9.

23. Sanchez M, Guadilla J, Fiz N, Andia I. Ultrasound-guided platelet-rich plasma injections for the treatment of osteoarthritis of the hip. Rheumatology (Oxford). 2012;51(1):144-50.

24. Andia I, Sanchez M, Maffulli N. Joint pathology and platelet-rich plasma therapies. Expert Opin Biol Ther. 2012;12(1):7-22.

25. Bennell KL, Hunter DJ, Paterson KL. Platelet-rich plasma for the management of hip and knee osteoarthritis. Curr Rheumatol Rep. 2017; 19(5):24.
26. Griffin JW, Hadeed MM, Werner BC, Diduch DR, Carson EW, Miller MD. Platelet-rich plasma in meniscal repair: does augmentation improve surgical outcomes? Clin Orthop Relat Res. 2015;473(5):1665-72.

27. Gnecchi M, Melo LG. Bone marrow-derived mesenchymal stem cells: isolation, expansion, characterization, viral transduction, and production of conditioned medium. Methods Mol Biol. 2009;482:281-94.

28. Zhang J, Wang JH. Platelet-rich plasma releasate promotes differentiation of tendon stem cells into active tenocytes. Am J Sports Med. 2010;38(12): 2477-86.

29. Zhang J, Yuan T, Zheng N, Zhou Y, Hogan MV, Wang JH. The combined use of kartogenin and platelet-rich plasma promotes fibrocartilage formation in the wounded rat Achilles tendon entheses. Bone Joint Res. 2017;6:231-44.

30. Zhou Y, Zhang J, Yang J, Narava M, Zhao G, Yuan T. Kartogenin with PRP promotes the formation of fibrocartilage zone in the tendon-bone interface. J Tissue Eng Regen Med. 2017:11:3445-56.

31. El-Said M, Emile SH. Regenerative medicine in treatment of fecal incontinence: do we understand how it works? Am J Obstet Gynecol. 2019; 220(3):291.

32. Marini JC, Forlino A. Replenishing cartilage from endogenous stem cells. N Engl J Med. 2012;366(26):2522-4

33. Pittenger MF, Mackay AM, Beck SC, Jaiswal RK, Douglas R, Mosca JD, Moorman MA, Simonetti DW, Craig S, Marshak DR. Multilineage potential of adult human mesenchymal stem cells. Science. 1999;284(5411):143-7.

34. Starke C, Kopf S, Petersen W, Becker R. Meniscal repair. Arthroscopy. 2009; 25(9):1033-44

35. Zellner J, Mueller M, Berner A, Dienstknecht T, Kujat R, Nerlich M, Hennemann B, Koller M, Prantl L, Angele M, et al. Role of mesenchymal stem cells in tissue engineering of meniscus. J Biomed Mater Res A. 2010; 94(4):1150-61.

36. Yu H, Adesida AB, Jomha NM. Meniscus repair using mesenchymal stem cells - a comprehensive review. Stem Cell Res Ther. 2015;6:86.

37. Khafagy WW, El-Said MM, Thabet WM, Aref SE, Omar W, Emile SH, Elfeki H, El-Ghonemy MS, El-Shobaky MT. Evaluation of anatomical and functional results of overlapping anal spincter repair with or without the injection of bone marrow aspirate concentrate: a case-control study. Color Dis. 2017; 19(1):066-074.38

38. El-Said MM, Emile SH. Cellular therapy: a promising tool in the future of colorectal surgery. World J Gastroenterol. 2019;25(13):1560-5.

39. Mei-Dan O, Mann G, Maffulli N. Platelet-rich plasma: any substance into it? Br J Sports Med. 2010;44(9):618-9.

40. Niu W, Guo W, Han S, Zhu Y, Liu S, Guo Q. Cell-based strategies for meniscus tissue engineering. Stem Cells Int. 2016;2016:4717184.

41. Giusti I, Rughetti A, D'Ascenzo S, Millimaggi D, Pavan A, Dell'Orso L, Dolo V. Identification of an optimal concentration of platelet gel for promoting angiogenesis in human endothelial cells. Transfusion. 2009;49:771-8.

\section{Publisher's Note}

Springer Nature remains neutral with regard to jurisdictional claims in published maps and institutional affiliations.

Ready to submit your research? Choose BMC and benefit from:

- fast, convenient online submission

- thorough peer review by experienced researchers in your field

- rapid publication on acceptance

- support for research data, including large and complex data types

- gold Open Access which fosters wider collaboration and increased citations

- maximum visibility for your research: over $100 \mathrm{M}$ website views per year

At $\mathrm{BMC}$, research is always in progress.

Learn more biomedcentral.com/submission 